\title{
Elements of Engagement in Promoting Social Acceptance of Mobile Augmented Reality Application
}

\author{
https://doi.org/10.3991/ijim.v14i17.16555 \\ Esraa Jaffar Baker $\left.{ }^{(}\right)$ \\ University of Mustansiriyah, Baghdad, Iraq \\ esraajafbaker67@gmail.com \\ Juliana Aida Abu Bakar, Abdul Nasir Zulkifli \\ Universiti Utara Malaysia, Kedah, Malaysia
}

\begin{abstract}
In a social context, Mobile Augmented Reality is a type of Augmented Reality which enables users to interact with the augmented environment. However, the degree of engagement and non-distraction of Mobile Augmented Reality has been of major concern to scholars. This is because Mobile Augmented Reality should be a focused, movable and engaged augmented environment which allows users to achieve the desired objectives. Therefore, this paper examines the engagement elements of Mobile Augmented Reality that promote social acceptance among users within the vast literature. These elements will enable Mobile Augmented Reality designers and developers to produce apps that will be able to enhance users' interest and attractiveness in a fun way. Based on the critical and comprehensive review, there are 22 elements of engagement that have been used by previous researchers in the design of Mobile Augmented Reality apps. The 22 elements include; Aesthetics, Novelty, Usability, Feedback, Motivation, Attention, Perceived Control, Curiosity, Enjoyment, Self-efficacy, Friendliness, Social skill, Endurability, Interest, Immersion, Challenge, Satisfaction, User Autonomy, Improvement, Supportive, Trust and Interaction. This paper argues that the 22 elements are critical in producing an engaging Mobile Augmented Reality app. It is recommended for designers to consider these elements in ensuring that the users will be positively engaged with the Mobile Augmented Reality app.
\end{abstract}

Keywords - Systematic Literature Review, Engagement Element, Mobile Augmented Reality, Mobile App.

\section{Introduction}

Augmented Reality (AR) introduces virtual objects into the real environment aimed at augmenting the environment. The augmented environment is derived from the superimposition of computer-generated objects onto the physical objects. Knowledge about AR has greatly affected human-computer interaction (HCI) with the proliferation of Mobile Augmented Reality (MAR) apps and the provision of social 
support in various domains ranging from healthcare to tourism. The benefits of MAR apps include environment-awareness, wearability, mobility, flexibility, reminders, multi-modal, and visual alerts that promote constructive social interaction. While it is beneficial to the societies and also the industries, presently, MAR apps have several limitations that include user experience, tracking and calibration, overload, depth perception, over-reliance, and outdoor and portability usage [1]. Several previous studies have focused on the technical issues of MAR while there is limited study among the literature that explores MAR engagement elements. Hence, this paper explores MAR engagement elements that promote MAR social acceptance among users. These elements enable designers and developers to produce MAR apps that are able to attract and enhance users' interest in a fun way to attract their attention in doing activities based on the app.

\section{Review of Literature}

Within the vast literature, AR has been widely applied in various fields. For example, AR has applied in the development of prototypes for the industries. AR is used to reduce the high cost in producing the actual prototypes and also prevent human from dangerous circumstances while testing the prototypes. The use of the AR prototypes enables companies to save time and money since the AR prototypes could be quickly changed and recreated. AR has been utilized in various fields including; engineering, education [54], heritage, archaeology, games, and many others. AR has been applied in visualizing archaeological landscapes and notation [2], [3], [4], [5] and [53]. It has also revolutionized the way architectural practices are implemented [6] and [7]. AR apps are also essential for previewing of products by integrating print and video marketing in the trade domain [8], [9] and [52].

However, AR is used extensively for learning purposes. AR-based learning includes a variety of apps that are aimed for cultural, historical, game, sightseeing and museum guidance. Although, the usefulness of MAR is huge however, the issue of users' experience is very imperative for the success of the MAR apps [10]. Users' experience is the engagement of the users' perception and reality with a given app which depends on their assessment of the app quality, service, and usage [11]. It refers to the user deep comprehension and feeling of the app which is rooted in if the app meets their need, value, abilities, and expectation. This is what informs the users' interaction with the app and from their conclusion about the app. User engagement experience demands that the user will be satisfied not only with the app design but also its efficiency. The issue of user engagement is very important for any app since it is also related to the users' satisfaction.

According to [12], user satisfaction can be enhanced by the app novelty, users felt involvement and endurability. It is believed that a novel app will attract and satisfy the users because it triggers the users' curiosity for unfamiliar or new experiences with the app. This experience becomes mysterious and conundrum which will increase the learning passion of the users with the app. Users will become more involved if there is an increased in the learning passion of the users with the app. This 
activation results in the user enjoyment and satisfaction with the app. On the other hand, endurability describes the likelihood of the user to return back to the usage of the app. This determines the user's continuous usage of the app which revolves around the value the users derive from the app. This value is usually based on the users' perceptions of the app to be rewarding to meet their expectation and determine their future recommendations to other users.

The elements of engagement are widely used in person-centered practice research such as behavioural change intervention and user-centred studies. According to [13], the elements of engagement involve the decision by a user to undertake the tasks (as given by the mobile app) related to his/her interest and competence, practice it continuously by interacting immensely and deeply in order to continue the task with persistence and commitment because of the value attributed to the task. [14] explained engagement in terms of multimedia perspective as a system that enables users' curiosity, attention focus, and intrinsic interest. In addition, [15] pointed out that engagement is the attribute that depicts the quality of user's value, experience and continuity with a mobile app. Similarly, many scholars have explained mobile app engagement in terms of users' attitude and behaviour [16], user stickiness [17], longterm retention [18], users' impact [19], and users' measure of comprehension on an app [20]. In summary, it can be concluded that the mobile app engagement is the number of users' counts to interact continuously with an app.

As established previously, engagement involves users' interest and competence. The elements of interest and competence are deeply rooted in the users' feeling and sense-making on the mobile app. According to [21], the elements of users' engagement with the mobile app are more than the user involvement interaction. Users' involvement depicts the interaction that is without feeling or compliance which will not result in engagement. A study by [22] shed light on the issue of mobile app engagement when discussing the three main engagement dimensions namely; behavioural, cognitive, and emotional. Behavioural engagement is when users show optimism, curiosity, passion and attention towards a mobile app which usually increase the motivation to learn. Cognitive engagement is when the users show critical thinking level by challenging themselves in the interaction with the mobile app. Emotional engagement is when users show affective tendencies such as the sense of belonging and fun with the mobile app. In order to fully comprehend the rationale for this issue, there is a need to explore the various elements of engagement in the mobile apps. Hence, this paper delves into the elements of MAR engagement for the mobile apps.

\section{$3 \quad$ Methodology}

This paper focuses on the elements of engagement that are required in designing a mobile app which will captivate the users' attention and involvement. In achieving the objectives of the study, a critical and comprehensive review has been employed based on [23]. It was utilized in identifying the elements of MAR which were accessed from the databases such as World Scientific, SpringerLink, IEEE and ScienceDirect. The 
keywords that were used for the search include AR, MAR, mobile app, engagement and engagement app. Combinatorial and interchangeable keyword search strategy was used to get more explicit and precise results. Following the search strategy, 116 studies were finally selected and all of them were critically reviewed. Based on the literature review, 22 elements of MAR have been identified from the vast literatures.

\section{$4 \quad$ Findings and Discussion}

The findings of this study yield 22 elements of MAR engagement that can be used for the design and development of MAR apps. These 22 elements include Aesthetics, Novelty, Usability, Feedback, Motivation, Attention, Perceived Control, Curiosity, Enjoyment, Self-efficacy, Friendliness, Social skill, Endurability, Interest, Immersion, Challenge, Satisfaction, User Autonomy, Improvement, Supportive, Trust and Interaction. The 22 elements are further discussed in the following sub-sections.

\subsection{Aesthetics}

It is a blend of art, beauty, and taste with MAR application [24]. Theory of beauty is introduced to users so that they appreciate the message conveyed by the MAR app. In a major study by [25], the element of aesthetics is identified as an evaluation and measurement factor for engagement.

\subsection{Novelty}

This element depicts the usage of MAR to teach and learn new behaviour and knowledge. The element ensures that the conveying message of the MAR is based on the principle of quality, originality and newness in order to achieve the target behaviour of the app. This element has been implemented in studies such as [26], [27] and [28] where it is argued that novelty enhances engagement. These studies pinpoint that when users know that the app is teaching new behavior, then their curiosity to explore the app will increase which will make them to be more engaged with the app.

\subsection{Usability}

This element consists of learnability, ease of use, and flexibility of MAR. Ease of use is one of the tools to measure and evaluate MAR apps [29]. Usability has been applied in [30], [31], [25], [24], [32] and [33] where usability stimulates users' satisfaction and engagement with the MAR app.

\subsection{Feedback}

It is related to users' responses and reactions to change aimed at promoting positive performance. [34] argue that when users perceive that their input and contribution to a system is vital then their engagement with the system will increase. This further 
support [30] that positive feedback information enhances passionate reactions and promotes positive performance.

\subsection{Motivation}

It is related to the potential of users to be ready and willing to do work [35]. Users are usually engaged with apps that inspire or encourage them towards excellence [36].

\subsection{Attention}

This is the act of gaining awareness and making message more fun and interesting to the user [37]. This element has been applied in studies by [25], [37], [36] and [38]. Their conclusion is that apps that have successfully gained users' attention will also succeed in engaging the users.

\subsection{Perceived control}

The element enables users to feel that they are controlling the situation or event in the app. It will be more intensified if more control is given to the users of the app. Perceived control has been used by [39] and [30] where it promotes engagement.

\subsection{Curiosity}

Curiosity describes the quality of curious thinking that will encourage users to search and investigate internally. It fosters informal learning where learning takes place through searching and exploring. Curiosity has been applied in studies by [40], [39], [31], and [36] which indicated that apps that boost users' interest can successfully engage users in a learning environment.

\subsection{Enjoyment}

Enjoyment is the feeling of reaping benefits from the message conveyed by the app. It comprises users feeling of fun, satisfaction, peace, fulfilment and joy after using the app [41].

\subsection{Social skill}

This is the ability to facilitate communication, relationship and interaction with others within the same social circle. Studies by [42] and [43] have highlighted that any app that facilitate social ability and skill enhances users' engagement. Social skill element implies that users are able to connect with others by forming bonding and circle. 


\subsection{Self-efficacy}

Self-efficacy is the belief of the users in their capability to be successful in certain circumstances or completing a work. Therefore, apps that are able to enhance the selfefficacy of users will also be able to engage them [44] and [38].

\subsection{Friendliness}

It is related to the app's ability to have good nature, amiability, good humour and affability. This element is vital in engagement because it promotes pleasant companions and social interactions which have been implemented by [45], [46] and [33].

\subsection{Endurability}

This is the ability for the user to bear and tolerate instructions from the app in order to perform the target action or behaviour. This element defines the likelihood of the user to return back to the usage of the app and has been explored in studies such as [40], [12], [38], and [25].

\subsection{Interest}

It is about getting the attention of users to participate in predefined activity or conduct. Previous studies by [12], [40] and [36] argue that the engagement of users can be achieved whenever the users are attracted to the app's message.

\subsection{Immersion}

The element of immersion defines the state of deep mental involvement of users based on their interaction with an app. This element implies that the user is able to experience deep thinking as a result of the app interaction. This element is well explained in the studies of [12], [40] and [36] where element of immersion is associated with engagement.

\subsection{Challenge}

The element of challenge involves a provocation to action or summons to compete and contest. Thus, an engaged app should be able to dare and persuade its users to perform the target action and behaviour. This element has been implemented and explained in previous studies such as [12], [40] and [48] and has been identified as a determinant of engagement. 


\subsection{Satisfaction}

It is about the creation of fun moments with the app when the users met their expectations with the app. Each user usually has specific goal when using an app and when this goal is achieved, the user will be engaged with the app and conversely [12], [40] and [48].

\subsection{User autonomy}

This is the element that defines the users' ability to set desires and goals where the app support and ensure that the predefined desires and goals are met or implemented. Based on [49], an improved user' autonomous learning ability will enhance the quality of engagement of the apps.

\subsection{Improvement}

This element pinpoints that the app users must see the perceived benefits in an app toward their defined behaviour or action. This implies that the app should be seen as a positive application which will enhance the users' target behaviour and actions [50] and [45].

\subsection{Supportive}

The application should be able to enhance the unachievable tasks performed previously by the users. The element of support depicts that the users can be encouraged and assisted in order to achieve the needed behaviour and action [51].

\subsection{Trust}

The element of trust defines the users' confidence in the workability of the app to achieve its defined objective and aim. The element is vital because without trust, it will be impossible for users to follow the instruction of the app. This element has been implemented in studies such as [36] and [40] where it is established that a trustful app will be more engaging to the user.

\subsection{Interaction}

It describes how the users and app are connected. The user's engagement with an app is affected by the nature and platform of the app's communication [40]. Therefore, it is critical to engagement when it comes to the ability to connect between the app and users [33].

Table 1 summarizes all the 22 MAR engagement elements that are considered to be the key elements required in the design and development of engaging MAR apps. 
Table 1. MAR Engagement Elements Based on SLR

\begin{tabular}{|c|c|c|c|}
\hline No & Elements & Description & Reference \\
\hline 1 & Aesthetics & $\begin{array}{l}\text { This element is the blend of art, beauty, and taste and with } \\
\text { MAR application. }\end{array}$ & {$[25],[24]$} \\
\hline 2 & Novelty & $\begin{array}{l}\text { The element that depicts the usage of MAR to teach and } \\
\text { learn new behaviour and knowledge. }\end{array}$ & {$[28],[27],[26]$} \\
\hline 3 & Usability & $\begin{array}{l}\text { The element consisting of learnability, ease of use, and } \\
\text { flexibility of MAR. }\end{array}$ & $\begin{array}{l}{[29],[25],[24]} \\
{[30],[31],[32],[33]}\end{array}$ \\
\hline 4 & Feedback & $\begin{array}{l}\text { Positive information that will enhance passionate reactions } \\
\text { which will promote positive performance. }\end{array}$ & {$[34],[30]$} \\
\hline 5 & Motivation & The ability of users to be ready and willing to do task. & {$[35],[36]$} \\
\hline 6 & Attention & Act of gaining awareness and making something interesting. & [25], [37], [36], [38] \\
\hline 7 & Perceived Control & $\begin{array}{l}\text { The element enables users to feel that they are controlling } \\
\text { the situation or event in the app. }\end{array}$ & {$[39],[30]$} \\
\hline 8 & Curiosity & $\begin{array}{l}\text { Act of increasing users' desire towards learning and } \\
\text { knowledge. }\end{array}$ & [40], [39], [31], [36] \\
\hline 9 & Enjoyment & $\begin{array}{l}\text { It is the feeling of reaping benefits from the message } \\
\text { conveyed by the app. }\end{array}$ & {$[41]$} \\
\hline 10 & Social skill & $\begin{array}{l}\text { It is the ability to facilitate interaction and communication } \\
\text { with others. }\end{array}$ & {$[42],[43]$} \\
\hline 11 & Self-efficacy & $\begin{array}{l}\text { It is the belief of the users in their capability to be successful } \\
\text { in certain circumstances or completing a work. }\end{array}$ & [44], [38] \\
\hline 12 & Friendliness & $\begin{array}{l}\text { The app's ability to have good nature, amiability, good } \\
\text { humour and affability. }\end{array}$ & {$[46],[45],[33]$} \\
\hline 13 & Endurability & $\begin{array}{l}\text { The likelihood of the user to returns back to the usage of the } \\
\text { app. }\end{array}$ & {$[25],[40],[38],[12]$} \\
\hline 14 & Interest & It should gain the involvement to act by the users. & [12], [36], [47], [40] \\
\hline 15 & Immersion & $\begin{array}{l}\text { The app should be able to cause deep mental involvement to } \\
\text { the users. }\end{array}$ & {$[12],[36],[47],[40]$} \\
\hline 16 & Challenge & The app should be able to provoke users to action. & {$[12],[40],[48]$} \\
\hline 17 & Satisfaction & It should create pleasing moments with the app. & {$[12],[40],[48]$} \\
\hline 18 & Learner Autonomy & $\begin{array}{l}\text { An improved users' autonomous learning ability and thus } \\
\text { improve the quality of app teaching. }\end{array}$ & [49] \\
\hline 19 & Improvement & $\begin{array}{l}\text { Users must see that the app can improve their behavior or } \\
\text { action. }\end{array}$ & {$[50],[45]$} \\
\hline 20 & Supportive & $\begin{array}{l}\text { The app should be able to enhance the users to perform } \\
\text { previously unachievable tasks. }\end{array}$ & {$[51]$} \\
\hline 21 & Trust & Users must have confident in the workability of the app. & {$[36],[32]$} \\
\hline 22 & Interaction & Ability to connects between users and app. & {$[40],[33]$} \\
\hline
\end{tabular}

Based on the literature review, 22 elements of MAR have been identified from the vast literatures. This implies that each of these 22 elements triggers engagement in the MAR app.

\section{Conclusion}

This paper discusses the key engagement elements that are vital to be applied in the design and development of MAR app. These elements are important in ensuring that the developed apps are able to capture users' attention and engagement. These 
elements include; Aesthetics, Novelty, Usability, Feedback, Motivation, Attention, Perceived Control, Curiosity, Enjoyment, Self-efficacy, Friendliness, Social skill, Endurability, Interest, Immersion, Challenge, Satisfaction, User, Autonomy, Improvement, Supportive, Trust and Interaction. This paper argues that these 22 elements are critical for the design and development of an engaging MAR app. It is crucial for the MAR apps' designers and developers to consider and incorporate some of these elements in their future MAR app in ensuring that the app's users are positively engaged when using the app. Although, this paper has presented 22 elements of MAR app engagement, further study is still needed to explore in more details the usefulness and impact of each element. In-depth studies on each of the elements can help designers and developers to understand the appropriate implementation of these elements in their MAR apps.

\section{Acknowledgement}

This research was supported by the Fundamental Research Grant Scheme (SO Code 14354) received from the Ministry of Higher Education Malaysia through the School of Creative Industry Management and Performing Arts, Universiti Utara Malaysia. Special thanks to the School of Creative Industry Management and Performing Arts, Universiti Utara Malaysia for the resources and support.

\section{$7 \quad$ References}

[1] D. W. F. Van Krevelen, and R. Poelman, A survey of augmented reality technologies, applications and limitations. International Journal of Virtual Reality, 9(2), 1, 2010. https://doi.org/10.20870/ijvr.2010.9.2.276

[2] S. Eve, Augmenting phenomenology: using augmented reality to aid archaeological phenomenology in the landscape. Journal of archaeological method and theory, 19(4), 582600, 2012. https://doi.org/10.1007/s10816-012-9142-7

[3] J. E, Swan and J. L. Gabbard, Survey of user-based experimentation in augmented reality. In Proceedings of 1st International Conference on Virtual Reality, 1-9, 2005.

[4] Vlahakis, J. Karigiannis, M. Tsotros, M, Gounaris, L, Almeida, D, Stricker, and N. Ioannidis, Archeoguide: first results of an augmented reality, mobile computing system in cultural heritage sites. In Virtual Reality, Archeology, and Cultural Heritage, 131-140, 2001. https://doi.org/10.1145/584993.585015

[5] V. Vlahakis, N. Ioannidis, J. Karigiannis, M. Tsotros, M. Gounaris, D. Stricker and L. Almeida. Archeoguide: an augmented reality guide for archaeological sites. IEEE Computer Graphics and Applications, (5), 52-60, 2002. https://doi.org/10.1109/mcg. 2002.1028726

[6] A. Hill, B. MacIntyre, M. Gandy, B. Davidson and H. Rouzati, Kharma: An open kml/html architecture for mobile augmented reality applications. In 9th IEEE International Symposium on Mixed and Augmented Reality ISMAR 2010, 233-234, IEEE, 2010. https://doi.org/10.1109/ismar.2010.5643583 
[7] A. Webster, S. Feiner, B. MacIntyre, W. Massie and T. Krueger, Augmented reality in architectural construction, inspection and renovation. In Proceedings of ASCE Third Congress on Computing in Civil Engineering, 913-919, 1996.

[8] Y. Lu and S. Smith, Augmented reality e-commerce assistant system: trying while shopping. In Human-Computer Interaction. Interaction Platforms and Techniques, 643652, Springer Berlin Heidelberg, 2007. https://doi.org/10.1007/978-3-540-73107-8 72

[9] J. Arrasvuori, Augmented reality assisted shopping. U.S. Patent Application 11/523,162, 2006.

[10] M. Hatala and R. Wakkary, Ontology-based user modeling in an augmented audio reality system for museums. User Modeling and User-Adapted Interaction, 15(3-4), 339-380, 2005. https://doi.org/10.1007/s11257-005-2304-5

[11] M. Pérez-Sanagustín, D. Parra, R. Verdugo, G, García-Galleguillos and M. Nussbaum, Using QR codes to increase user engagement in museum-like spaces. Computers in Human Behavior, 60, 73-85, 2016. https://doi.org/10.1016/j.chb.2016.02.012

[12] D. Permadi and A. Rafi, Developing a Conceptual Model of User Engagement for MobileBased Augmented Reality Games. Jurnal Teknologi, 77(29),9-13, 2015. https://doi.org/10.11113/jt.v77.6804

[13] G. Kearsley and B. Shneiderman, Engagement Theory: A Framework for TechnologyBased Teaching and Learning. Educational technology, 38(5), 20-23. 1998

[14] P. Chapman, S. Selvarajah and J. Webster, Engagement in multimedia training systems. In Proceedings of the 32nd Annual Hawaii International Conference on Systems Sciences HICSS, IEEE, 1999. https://doi.org/10.1109/hicss.1999.772808

[15] H. L. O'brien and E. G. Toms, what is user engagement? A conceptual framework for defining user engagement with technology. Journal of the American society for Information Science and Technology, 59(6), 938-955, 2008. https://doi.org/10.1002/ $\underline{\text { asi. } 20801}$

[16] H. Du, A. Venkatakrishnan, G. M. Youngblood, A. Ram and P. Pirolli, A Group-Based Mobile Application to Increase Adherence in Exercise and Nutrition Programs: A Factorial Design Feasibility Study. JMIR mHealth and uHealth, 4(1), 2016. https://doi.org/10. 2196/mhealth.4900

[17] J. Huizenga, W. Admiraal, S. Akkerman and G. T. Dam, Mobile game-based learning in secondary education: engagement, motivation and learning in a mobile city game. Journal of Computer Assisted Learning, 25(4), 332-344, 2009. https://doi.org/10.1111/ j.1365-2729.2009.00316.x

[18] H. Pavliscsak, J. R. Little, R. K. Poropatich, F. L. McVeigh, J. Tong, J. S. Tillman and S. J. Fonda, Assessment of patient engagement with a mobile application among service members in transition. Journal of the American Medical Informatics Association, 23(1), 110-118, 2016. https://doi.org/10.1093/jamia/ocv121

[19] L. Kosinski, C. Baum, M. Sorensen, J. Rosenberg, D. Sales, B. Blumenstein and M. Haverty, P-208 Project Sonar: Improvement in Patient Engagement Rates Using a Mobile Application Platform. Inflammatory Bowel Diseases, 22(suppl_1), S72-S72., 2016. https://doi.org/10.1097/01.mib.0000480324.18611.51

[20] Y. H. Kim, D. J. Kim and K. Wachter, A study of mobile user engagement (MoEN): Engagement motivations, perceived value, satisfaction, and continued engagement intention. Decision Support Systems, 56, 361-370, 2013. https://doi.org/10.1016/ j.dss.2013.07.002

[21] S. R. Harper and S. J. Quaye, Beyond sameness, with engagement and outcomes for all. In Student engagement in higher education, 29-44, Routledge, 2009. 
[22] J. A. Fredricks, P. C. Blumenfeld and A. H. Paris, School engagement: Potential of the concept, state of the evidence. Review of educational research, 74(1), 59-109, 2004. https://doi.org/10.3102/00346543074001059

[23] I. M. Santos and N. Ali, Exploring the uses of mobile phones to support informal learning. Education and Information Technologies, 17(2), 187-203, 2012. https://doi.org/10. $1007 / \mathrm{s} 10639-011-9151-2$

[24] T. L. Huang and S. Liao, A model of acceptance of augmented-reality interactive technology: the moderating role of cognitive innovativeness. Electronic Commerce Research, 15(2), 269-295, 2015. https://doi.org/10.1007/s10660-014-9163-2

[25] H. L. O'Brien and E. G. Toms, the development and evaluation of a survey to measure user engagement. Journal of the American Society for Information Science and Technology, 61(1), 50-69, 2010.

[26] B. Patzer, D. C. Smith and J. R. Keebler, Novelty and retention for two augmented reality learning systems. In Proceedings of the Human Factors and Ergonomics Society Annual Meeting, 58(1), 1164-1168, SAGE Publications, 2014. https://doi.org/10.1177/ 1541931214581243

[27] G. Assaker, V. E. Vinzi and P. O'Connor, Examining the effect of novelty seeking, satisfaction, and destination image on tourists' return pattern: A two factor, non-linear latent growth model. Tourism Management, 32(4), 890-901, 2011. https://doi.org/10. 1016/j.tourman.2010.08.004

[28] T. H. Lee and J. Crompton, measuring novelty seeking in tourism. Annals of tourism research, 19(4), 732-751, 1992. https://doi.org/10.1016/0160-7383(92)90064-v

[29] J. Sauro, Measuring usability with the system usability scale (SUS). Available: http://www. measuringusability.com/sus.Php, 2015.

[30] T. S. Hector and G. F. Payel, Analysis of Four Usability Evaluation Methods Applied to Augmented Reality Applications, 2014.

[31] C. Pribeanu, Extending and Refining Usability Heuristics to Better Address User Centered Design Issues in the Development and Evaluation of Municipal Websites. Informatica Economica, 18(1), 83, 2014. https://doi.org/10.12948/issn14531305/18.1.2014. $\underline{07}$

[32] S. Nilsson and B. Johansson, Fun and usable: augmented reality instructions in a hospital setting. In Proceedings of the 19th Australasian conference on Computer-Human Interaction: Entertaining user interfaces, 123-130, ACM, 2007.

[33] A. C. Haugstvedt, Accessing Cultural Heritage Resources on a Mobile Augmented Reality Platform: A Study on Technology Acceptance. Master's thesis, Institutt for datateknikk og informasjonsvitenskap, 2012.

[34] A. Mouratidis, M. Vansteenkiste, W. Lens and G. Sideridis, The motivating role of positive feedback in sport and physical education: Evidence for a motivational model. Journal of sport \& exercise psychology, 30(2), 240, 2008. https://doi.org/10.1123/ jsep. 30.2 .240

[35] M. Alqahtani and H. Mohammad, Mobile Applications' Impact on Student Performance and Satisfaction. Turkish Online Journal of Educational Technology-TOJET, 14(4), 102 112, 2015. https://doi.org/10.1016/j.compedu.2012.03.002

[36] A. Di Serio, M. B. Ibáñez and C. D. Kloos, Impact of an augmented reality system on students' motivation for a visual art course. Computers \& Education, 68, 586-596, 2013.

[37] J. Ferrer-Torregrosa, J. Torralba, M. A. Jimenez, S. García and J. M. Barcia, ARBOOK: development and assessment of a tool based on augmented reality for anatomy. Journal of Science Education and Technology, 24(1), 119-124, 2015. https://doi.org/10.1007/ $\underline{\text { s10956-014-9526-4 }}$ 
[38] R. Wojciechowski and W. Cellary, Evaluation of learners' attitude toward learning in ARIES augmented reality environments. Computers \& Education, 68, 570-585, 2013. https://doi.org/10.1016/j.compedu.2013.02.014

[39] M. Boberg, E. Karapanos, J. Holopainen, and A. Lucero, PLEXQ: Towards a Playful Experiences Questionnaire. In Proceedings of the 2015 Annual Symposium on ComputerHuman Interaction in Play, 381-391, ACM, 2015. https://doi.org/10.1145/27931 07.2793124

[40] A. Nachairit and N. SrisawasdI, Using Mobile Augmented Reality for Chemistry Learning of Acid-base Titration: Correlation between Motivation and Perception, In Proceedings of the 23rd International Conference on Computers in Education, 519-528, 2015.

[41] D. M. Bressler and A. M. Bodzin, A mixed methods assessment of students' flow experiences during a mobile augmented reality science game. Journal of Computer Assisted Learning, 29(6), 505-517, 2013. https://doi.org/10.1111/jcal.12008

[42] H. Y. Wang, C. Liao and L. H. Yang, what affects mobile application use? The roles of consumption values. International Journal of Marketing Studies, 5(2), 11, 2013.

[43] L. Escobedo, D. H. Nguyen, L. Boyd, S. Hirano, A. Rangel, D. Garcia-Rosas and G. Hayes, MOSOCO: a mobile assistive tool to support children with autism practicing social skills in real-life situations. In Proceedings of the SIGCHI Conference on Human Factors in Computing Systems, 2589-2598, ACM, 2012. https://doi.org/10.1145/2207676. $\underline{2208649}$

[44] Y. Y. Mun and Y. Hwang, Predicting the use of web-based information systems: selfefficacy, enjoyment, learning goal orientation, and the technology acceptance model. International journal of human-computer studies, 59(4), 431-449, 2003. https://doi.org/10.1016/s1071-5819(03)00114-9

[45] D. D. McMahon, Augmented Reality on Mobile Devices to Improve the Academic Achievement and Independence of Students with Disabilities, Doctoral dissertation, University of Tennessee, 2014.

[46] P. E. Pedersen, L. B. Methlie and H. Thorbjornsen, Understanding mobile commerce enduser adoption: a triangulation perspective and suggestions for an exploratory service evaluation framework. In Proceedings of the 35th Annual Hawaii International Conference on System Sciences HICSS, IEEE, 2002. https://doi.org/10.1109/hicss.2002. $\underline{994011}$

[47] U. C. Pendit, S. B. Zaibon, J. Aida J. A. A. Bakar, Conceptual Model of Mobile Augmented Reality for Cultural Heritage Site towards Enjoyable Informal Learning Aspect. Jurnal Teknologi, 77(29), 2015. https://doi.org/10.11113/jt.v77.6847

[48] T. L. Chou L. J. Chanlin, Location-Based Learning through Augmented Reality. Journal of Educational Computing Research, 51(3), 355-368, 2014. https://doi.org/10.2190/ec. 51.3.e

[49] D. R. Chen, M. Y. Chen, T. C. Huang W. P. Hsu, Developing a mobile learning system in augmented reality context. International Journal of Distributed Sensor Networks, 2013.

[50] L. F. Capretz, A. Ali and A. Ouda, A conceptual framework for measuring the quality aspect of mobile learning. Bulletin of the IEEE Technical Committee on Learning Technologies, 14(4), 31-34, 2012.

[51] D. Datcu, S. Lukosch, H. Lukosch and M. Cidota, using augmented reality for supporting information exchange in teams from the security domain. Security Informatics, 4(1), 1, 2015. https://doi.org/10.1186/s13388-015-0025-9

[52] S. Abou El-Seoud and I. Taj-Eddin, An android augmented reality application for retail fashion shopping. International Journal of Interactive Mobile Technologies (iJIM), 13(1), 4-19, 2019. https://doi.org/10.3991/ijim.v13i01.9898 
[53] S. Boonbrahm, P. Boonbrahm, C. Kaewrat, P. Pengkaew and P. Khachorncharoenkul, Teaching Fundamental Programming Using Augmented Reality. International Journal of Interactive Mobile Technologies (iJIM), 13(7), 31-43, 2019. https://doi.org/10.3991/ ijim.v13i07.10738

[54] F. N. Rusli, A. N. Zulkifli, M. N. Saad and Y. M. Yussop, (A Study of Students' Motivation in Using the Mobile Arc Welding Learning App. International Journal of Interactive Mobile Technologies (iJIM), 13(10), 89-105, 2019. https://doi.org/10. 3991/ijim.v13i10.11305

\section{Authors}

Esraa Jaffar Baker is a lecturer in Computer Science at the Mustansiriyah University, Iraq. Her primary research interest focuses on multimedia systems, augmented reality, virtual reality and multimedia steganography. Her recent publications are in AIP Publishing, International Journal of Innovative Technology and Exploring Engineering and Journal of Telecommunication, Electronic and Computer Engineering (JTEC). Email: esraajafbaker67@gmail.com

Juliana Aida Abu Bakar currently is an associate professor at the School of Creative Industry Management \& Performing Arts, Universiti Utara Malaysia. She has won gold medals for innovative products in numerous exhibitions at national and international level and successfully lead two projects funded by national grants for the past five years. She has published over 100 articles in the renowned journals and proceeding with an h-index 6 . Her research interests include virtual reality design, development and evaluation augmented reality; and virtual heritage. Email: liana@uum.edu.my

Abdul Nasir Zulkifli is an Associate Professor at the School of Creative Industry Management \& Performing Arts, Universiti Utara Malaysia. He has been teaching in various fields including Mechanical Engineering, Manufacturing Engineering, CAD, CAM, Management of Technology, Multimedia, Virtual Reality and 3D Animation for the last 34 years. His research areas include Virtual Reality, Augmented Reality, and Mobile applications in training and education. Email: nasirzul@uum.edu.my

Article submitted 2020-06-25. Resubmitted 2020-07-26. Final acceptance 2020-07-27. Final version published as submitted by the authors. 